\title{
Design Intervention \& Craft Revival with Reference to Pichwai Paintings: A Contemporise Approach
}

\author{
Dr. Shruti Tiwari ${ }^{1 *}$, Divya Dhakad ${ }^{2}$ \\ ${ }^{1}$ Head of fashion, Renaissance University, India \\ ${ }^{2}$ MFT (Master's in fashion Technology), School of fashion, Renaissance University, India
}

*Corresponding author: Dr. Shruti Tiwari, School of fashion, Renaissance University, Indore, India.

Received Date: June 03, 2020

Published Date: June 30, 2020

\footnotetext{
Abstract models and create new range of products. opening new avenues in the global market.

Keywords: Traditions; Paintings; Craft revival; Design interventions

Objective

- To revitalize this rare traditional art of Pichwai.

- $\quad$ To give new dimensions to this traditional art yet maintaining its value.

- To enhance the livelihood and to create employment opportunities for artisans.

- To create market segment for artisans at global level.
}

The purpose of this study is to ensure if design intervention helps in the revival of dying craft with interesting ideas with new intervention

Design/Methodology/Approach: This study is based on a review of the literature and takes a case study approach. The study aims to suggest interventions as bridge between designers and craft persons to enhance and expand the craft vocabulary and reviving dying craft tradition and

\section{Introduction}

Indian handicrafts are unique expressions of a particular culture or community through local craftsmanship and materials. With increasing globalization, however, products are becoming more and more contemporized and artisans find their products competing with goods from all over the world.

This kind of demand regarding a product and change its style, design and color creates a great threat for the producer artisans and push these conventional handmade products out, replacing them with mass factory made, machine crafts [1].

Though the Indian traditional crafts based on skills, has been transformed from generation to generation and many of them are still making their livelihood dependent on the indigenous modes of production, traditional skills and techniques to manufacture products. 
Handicraft is the second largest source of employment in the country, after agriculture. Yet India's hand industries are in a crisis of misunderstanding. Crafts Council of India- 2011.

According to United Nations, over the past 30 years, the number of Indian artisans has decreased by 30\% indicating the need to reinvest in artisans to safeguard history culture and an important source of livelihood. -William Bissel, MD, Fabindia [2].

Among the oldest devotional paintings of India, the temple hangings of the Vallabhacharya Sampradaya, Krishna sect are one of the beautiful and mesmerizing ones. This painting style originated 400 years ago. The intricate and visually stunning devotional pictures on cloth or paper which portrays the tales from lord Krishna's life. These hangings act as a backdrop and adorn the walls of garbgriha of lord Krishna's temple.

These paintings are mainly done by the artist of the town Nathdwara, near Udaipur city . It is known as the center of Pichwai paintings. The artists here earn their livelihood through these paintings. The Pichwai artists belong to the communities of the jangidas and the Adi gauras [3].

\section{Review of Literature}

This research is inspired by the fact that crafting objects by hand is one of the defining traits of being human, then our present state of culture in which craft has disappeared in the "overdeveloped" world and it should cause us to pause and think about what is about to disappear.

Craft today is defined by preciousness, and an extraordinary value is attributed to the handmade craft as an exotic species. Caught between a rock and a hard place, people in the west fetishize the object, while in our world we romanticize the humble craftsman and his poor condition.

But neither of these approaches really looks past the artefact (as either a fetish or a commodity) to the role of craft as a catalyst for spurring thought and innovation in the society.

We may lament the loss of the beautiful objects we now see in museums, but what if the ultimate value of craft lies not in the artefact but rather in the process by which it comes to be? [4].

A study by Soteriou A [5] says that it is a process which seems to be getting lost as the artisans are trained in the art form by their ancestors over generations and craft was not about making a simple product. Rather it was about a historic legacy of generations and centuries, a tedious brutal labor and a proud skill, a battle between tradition and industrial modernity an expression of unique style and a vision of revival all connected to the heart and spirit of each individual artisan.

Research by Kasturi PB [6] reveals that - Has Indian design, in fifty years of the country's independence, empowered the crafts community to become "freshly evolved and seek solutions themselves." On how to resolve this problem of designing for new markets? Have designers asked the right questions of the crafts community to lead to such empowerment?

Perhaps it is now time to do so. "With adequate social opportunities, individuals can effectively shape their own destiny and help each other. They need not be seen as primarily as passive recipients of the benefits of development programs."

While design intervention in craft is welcomed by some as a necessity and an opportunity for exploring new prospects and help in craft revival, it is often considered as a threat by others [7].

In short, collaborative innovation between designer and craftsperson is a good means of expanding the craft vocabulary and tapping contemporary markets.

\section{Defining Craft}

Crafts can be defined as "those activities that deal with the conversion of specific materials into products, using primarily hand skills with simple tools and employing the local traditional wisdom of craft processes. Such activities usually form the core economic activity of a community of people called "craftsmen".

One definition state that crafts developed out of necessity to fulfil everyday needs of people. The products and objects made were for personal use and were instrumental in expressing their individuality and their way of life.

In the Indian context crafts have been both for personal use and an expressional fulfilment and economic activity. It evolved out of being a product of use, then was ornamented and given an aesthetic appeal to it.

A craftsperson is one who is skilled in a technique and though he may produce a number of similar objects, each one however expresses the maker's creativity [8].

It can also be defined as a personal journey of the craftsperson where the main objective is self-expression. The personalization, imperfections imparted because of hard work and use of indigenous tools and skills are the factors that differentiate "craft" from a community. (Design Intervention and its execution in crafts in India, Amita Pandey) [9] (Figures 1-3).

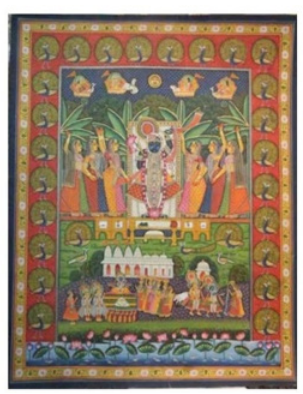

Figure 1: The detailed and intricate work in the foreground and background be it Shreenathji, Gopi's, temple architecture, flora and fauna in colored form with small detailing possible. 

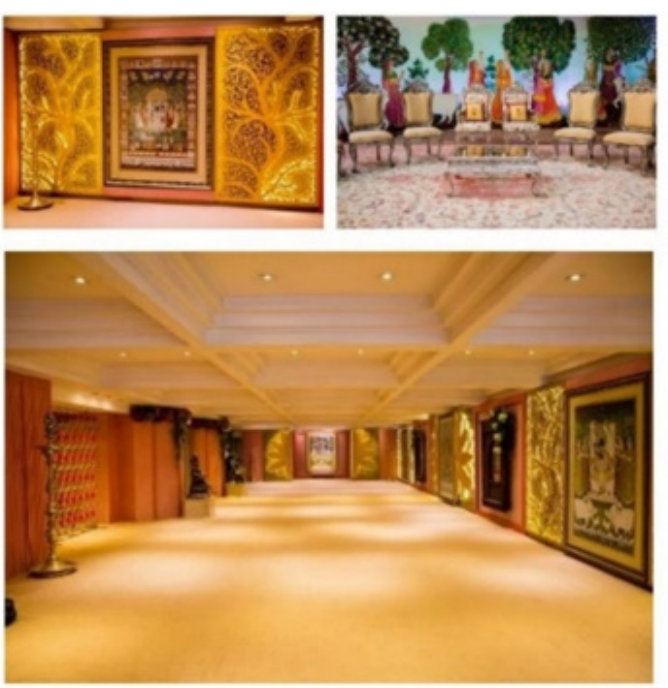

Figure 2: Use of Pichwai in Pre-wedding decor by Abu Jani and Sandeep Khosla.

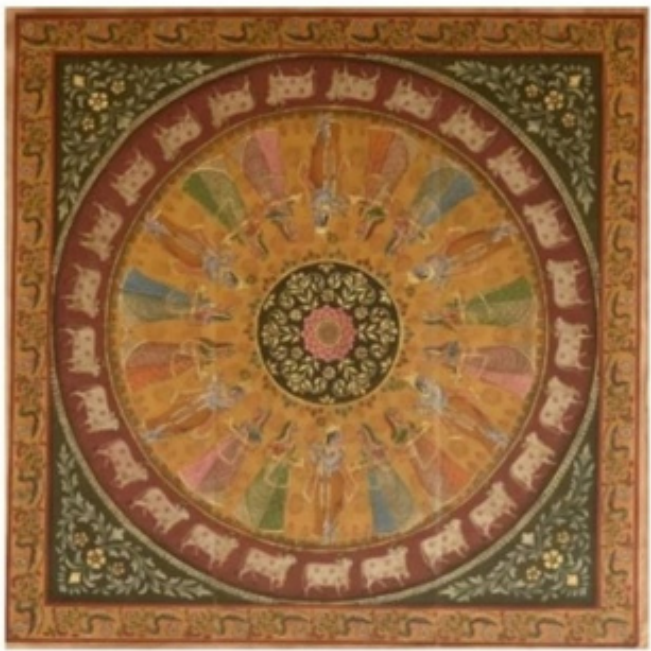

Figure 3: Pichwai painting of Raas-Leela.

The painting of Pichwai was painted on the handspun starched with charcoal which is known as Tipan and then the decorative and cotton fabric. The rough sketching is then done on starched fiber beautiful images were created (Figures 4\&5).
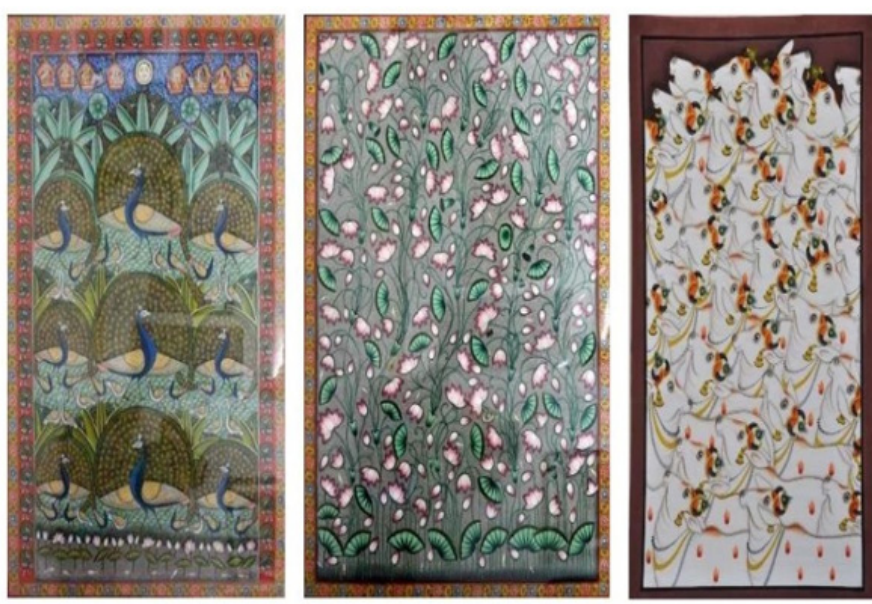

Figure 4: Pichwai paintings of different seasons. 


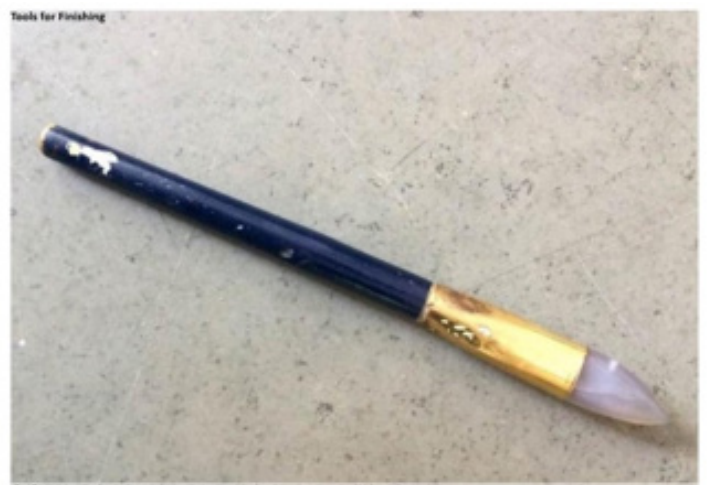

Figure 5:

Then the images are painted with completely organic and natural paints and natural brushes "kalam" made with squirrel, goat hair and bamboo stick. The colors are obtained from mineral compounds such as coals, indigo, gold, silver, zinc, and vegetable extract such as kesari from saffron, mauve and magenta from beetroot and pomegranate, wine from grapes. The ornate part is painted with pure gold.

Last but not the least, the most important part of painting that is ornamentation which is done with the help of pearls, crystals ,rubies and the gold ornaments were rubbed with agate stone 'ophani' to give them gloss. The transparency in garment is shown by using light wash, so that the inner garment remains visible(sari odhni).

\section{Current Status of Craft Industry}

Today, an argument, an attitude faces crafts and artisans in India. This is an argument of economics of sustainability, of marketability, which is the argument of financial survival (Crafts Council of India - April 2011).

One question is still unsolved and unanswered. What is the state of craft and craftsmen in India? This question carries a huge and thick question mark at its end.

While crafts received royal and aristocratic patronage during Pre-Independence days and played a central role in Gandhiji's independence struggle, they have slowly lost relevance with the advent of industrialization. Traditional crafts have largely been marginalized by mass produced consumer goods, which tend to be cheaper due to the economics of scale associated with mechanization.

The nature of the crafts sector and challenges faced by artisans reduces their ability to compete with machine made products. Catering to mainstream market often necessitates a decline in quality and/or workmanship, leading to the eventual loss of skills over a few generations.

\section{Factors Affecting the Craft Traditions}

Artisans are traditionally an essential part of the village economy producing everyday utilitarian objects catered towards local market using designs and motifs that were of significance to their communities.

However, with the advent of industrialization and increasing urbanization of markets for crafts the historical artisan-consumer relationship has broken down, and largely been replaced by traders. This has rendered artisan's knowledge and skill, acquired over generations, virtually useless and made crafts an unsustainable source of livelihood. (Crafting a livelihood -building sustainability for Indian Artisans, William Bissel, Managing Director, Fab India).

In the recent past, globalization has brought great changes across the world. The key characteristics of today's global market is the speed with which the demand for a product and change in its lifestyle, design, and color, offer greater opportunities as well as threats to producers.

The precarious nature of handmade craft markets invites strategic approaches to reach global consumers. But delayed response can push these deep-rooted traditional handmade products out, replacing them with mass factory made products, machine crafts [10].

\section{Roots of Indian Design}

Art and crafts have always been an integral part of India's rich tradition and heritage. They are in fact the cultural symbols of the nation. These art forms are unique and demand a high adroitness. The artisans are trained in the art form by their ancestors over generations.

Historically, it is evident from the mohenjodaro-harappa excavations that, as early as $2500 \mathrm{BC}$, there was highly developed architecture, town planning, and technology in many places. India's traditional knowledge was highly organized and meticulously articulated. Even in the arts, there was extremely detailed canons and highly sophisticated structured treaties.

\section{Challenges Faced by Pichwari Artists}

Natural and organic colors are not available these days. In present scenario, artisans are not earning sufficient funds as per their hard work, the reason being that a large amount of profit is taken by the middlemen i.e. commission agents and traders. 
Pichwai art is very byzantine and requires a lot of time (3-9months). And even after all those efforts one puts into it, there are very few buyers for it as it comes at a price not many want to pay. On the contrary, people prefer buying embossed and digitized work as it comes at a cheaper rate.

The younger generation of Pichwari painters is losing interest in thus art as it requires time and dedication but the perks of doing it are very less which doesn't support their expenses. The government is not providing any support to artisans of Pichwari which has led to further deterioration of the present condition of artisans.

\section{Design Intervention}

Design is currently considered a cross functional and multidisciplinary innovation activity, capable of making sense of social challenges to support competitiveness. It is considered a fundamental ingredient in business innovation through its ability to shape ideas and translate them into practical and appealing propositions for users, while improving national performance [11].

Pichwai painting and its motifs has been used in their contemporized version in the field of designing costumes, jewellery and accessories by many designers like Anita Dongre, Satya Paul, Neeta Lulla, Prashant and Shweta Garg. For examplebridal costumes with floral motifs showcased in Vogue magazine by Anita Dongre on Pichwai paintings.

Design intervention is a process which involves designing new products, redesigning existing products, with changes in shape, size, color, surface manipulation, function and utility, exploring new markets, applying traditional skills to meet new opportunities and challenges, and the production of new materials, new processes, new tools and technologies (Figures 6-8).

Figure 6:
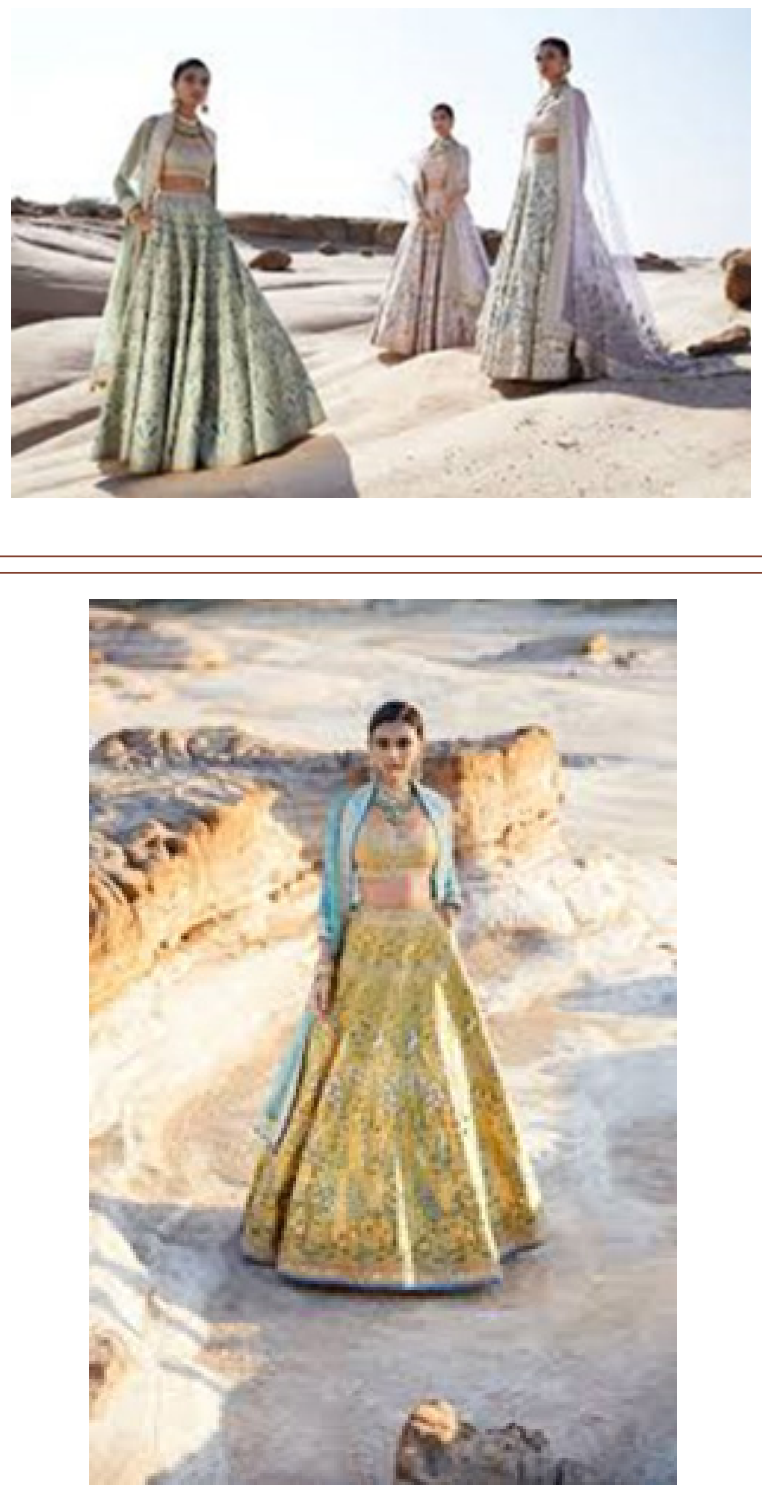

Figure 7: 
Figure 8:

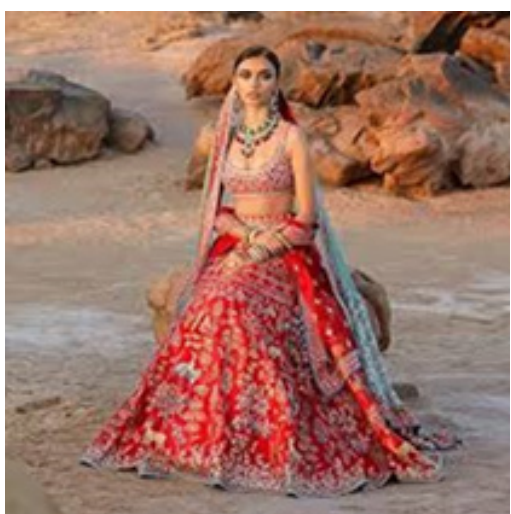

It is seen as an interface between tradition and modernity that matches craft production to the needs of modern living. Design interventions have a very important role in every step of the process in creation of the craft. They should focus on the identity of a craft, its social and cultural relevance to the region, and the processes and materials involved, to incorporate the interventions in the right situations, with efficient expected outcomes and reasoning's. (Design Intervention and its execution in crafts of India-Amrita Panda) (Figures 9\&10).

Figure 9:

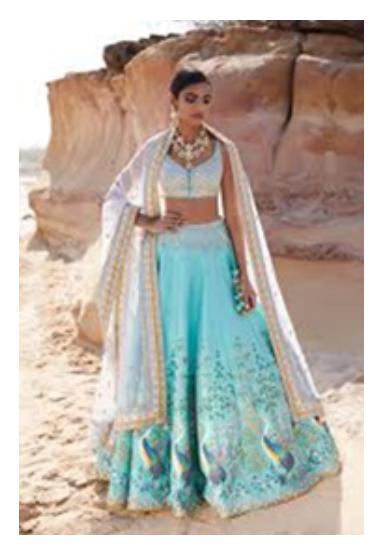

Figure 10:

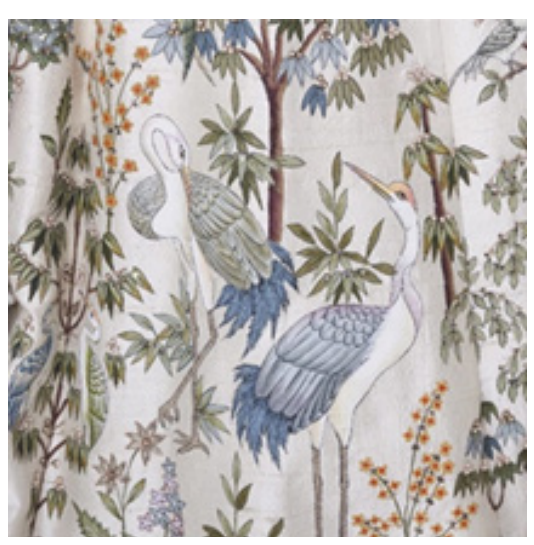

Design interventions also assist in creating an awareness among artisans of methods, materials, tools processes and clientele base. In many cases the artisans of a region have rather lost or do not have a documented form of the craft. Traditional crafts are memory based and only memory is the knowledge bank of traditional methods and materials (Design intervention and its execution in crafts of IndiaAmrita Panda).

\section{Revival of Craft}

As consumers, we're more aware of materials now- not just their visual and sensual appeal, but also where they come from, why they matter.We are more curious about how things are made and who made them [12].

Collaborative innovation between designer and craftsperson is a means of expanding the craft vocabulary and tapping 
contemporary markets [13]. It is also argued that a link between the apparently conflicting tenets of sustainability can be achieved through responsible and strategic design innovation which integrates the social, economic , ecological, cultural aspects [14].

These innovations, as they will be mostly in the form of appropriate modifications in the existing products, will require further critical interventions and hand holding efforts of their transition into markets.

Design intervention can help bring the much-needed empathetic understanding and holistic vision to connect and integrate the various efforts towards a positive outcome. One would come across amazing indigenous innovations in India that can help in creating business success. These could provide vital directions for a country like India, to transform into an innovation-driven economy. (Ascertaining the scope for design interventions for their successful commercialization- Ravi Mokashi punekar, Shashank Mehta-2011).

\section{Acknowledgement}

None.

\section{Conflict of Interest}

Authors declare no conflict of interest.

\section{References}

1. Wooley M (2011) Beyond control: Rethinking industry and craft dynamics Coventry
2. Bissel W, managing director, Fabindia (2013) Crafting a livelihoodBuilding sustainability for Indian Artisans.

3. (2016) Alastair Fuad-Luke, towards sustainable production and consumption- the role of craft designer-makers.

4. Risatti H (2008) Craft and Design- What's the Distinction?

5. Soteriou A(1998) Reviving a Tradition- Giving Papermaking Back to India.

6. Kasturi PB (2002) Designing freedom.

7. Balaram S (2005) Design Pedagogy in India: A Perspective. Massachusetts Institute of Technology, Design 21(4).

8. Dhamija J (2003) From then till now.

9. Panda AM (2012) Design Intervention and its execution in Crafts of India.

10. Vedakepat VM (2012) Globalizing Rural Markets: Evidence from handmade traditional product markets. Global journal of Business Research 6(4).

11. Mortati M, Vellari B (2003) Crafting social innovators: Designing collaborative participative networked solutions in urban contexts.

12. Lovelace J (2013) Handmade in India (World Bank Report 2004), the Craft of Design.

13. Niedderer K (2010) Craft Research and its context UK, University of Wolverhampton, UK.

14. Mehta S (2010) Design to Connect.......encouraging Social Innovation and Sustainability. 